\title{
Global crime trends during COVID-19
}

\author{
The COVID-19 pandemic has provided a natural experiment capable of answering a vital question: have \\ stay-at-home orders impacted global crime trends? A new study by Nivette and colleagues demonstrates that \\ crime largely decreased around the globe during COVID-19 stay-at-home orders-a finding which likely carries \\ international implications for crime policy.
}

\section{John H. Boman IV and Thomas J. Mowen}

T he COVID-19 pandemic has dramatically altered the landscape of human life across the globe. Upon realizing the potential severity of the virus, governments throughout the world began issuing stay-at-home orders around the end of the first quarter of 2020 . While intended to protect life and curb rapidly rising COVID-19 infection and fatality rates, these 'lockdowns' offered a once-in-several-generations disruption to human existence. While such mandates appear to have been successful at limiting COVID-19 infection and fatality rates, they were put into place with little historical precedent and virtually no understanding as to how they would affect life. Amid considerable attention paid to unintended consequences of stay-at-home orders, public safety officials, politicians, criminologists, the media, and the public have been all asking the same question: how has COVID-19 impacted crime across the globe? An article by Nivette and colleagues ${ }^{1}$ appearing in this issue of Nature Human Behaviour has finally answered this question-and the answer is, like most things in the world of crime research, complicated.

Using daily crime count data from police agencies, Nivette and colleagues investigate how stay-at-home orders impacted assault, theft, burglary, robbery, vehicle theft, and homicide across 27 cities in 23 countries worldwide. Nivette and colleagues reach five main conclusions:

1. Overall, crime decreased $37 \%$ worldwide after stay-at-home orders were issued by governments.

2. Some crimes decreased more than others. Property-based crimes decreased substantially, but homicide was relatively unchanged.

3. The extent to which stay-at-home orders impacted crime was heavily dependent on location.

4. Cities with more stringent lockdowns experienced greater crime decreases than cities with less stringent lockdowns.

5. As stay-at-home orders gradually eased, crime slowly increased to pre-COVID-19 levels.

Cast against the backdrop of a natural experiment, Nivette and colleagues' study carries significant importance for the study of crime. While the overall pattern of findings is key, this study is ground-breaking beyond the framework of COVID-19. In their study, the Nivette team addresses an issue that has plagued social scientists for generations: to prevent crime, should we reduce the opportunity for crime, decrease offender motivation, or both? On an international scale, this study shows that crime within a city can be drastically reduced through changes in opportunity only. Reducing criminal offending does not require direct change to the motivation of offenders.

Despite there being numerous studies on crime during COVID-19 (ref. ${ }^{2}$ ), global research on the pandemic and crime is rare. The most important reason for this is a lack of international data. Prior to Nivette and colleagues' study, researchers have commonly used easily available illustrative data $^{3}$, daily crime data from one city ${ }^{4}$, or daily crime data from a group of cities in one country ${ }^{5}$. While findings from these studies continue to be informative, the world of crime research has changed with the Nivette et al. study. With an impressive data collection effort, Nivette's team has amassed the most comprehensive, exhaustive, and authoritative dataset on COVID-19 and crime within an international context that currently exists.

Despite the Nivette team's study producing important findings, an eye to the future is always necessary. The Nivette et al. dataset-which they are willing to share with researchers-must grow to answer additional, and equally important, questions. While the possibilities for future research are numerous, we see three immediately necessary avenues: (1) expanding the data; (2) further exploring homicide; and (3) expanding beyond lockdowns. Prior to offering some concluding remarks on the broader importance of the Nivette team's research for international crime policy, we briefly discuss the need to further explore each of these three avenues of research.

First, using several data sources ${ }^{6-9}$, we estimate that the combined population of the 27 cities analysed by Nivette and colleagues is approximately 126.25 million people. Based on a global population of 7.8 billion (ref. ${ }^{10}$ ), the Nivette team's data cover only $1.62 \%$ of the global population. And-as recognized by the authors-the data over-represent cities in the Americas, Europe, and Asia. The inclusion of African and Middle Eastern cities and the expansion of currently under-represented geographical locations (e.g., Oceania, Southeast Asia) is imperative for these data specifically and for future international research on COVID-19 and crime generally.

Second, in the Nivette et al. study, homicide was not extensively impacted by COVID-19 stay-at-home orders. However, several cities were removed from their homicide analyses due to having zero or near-zero homicides (see the Nivette team's supplemental information). Due to the challenges of analysing very low frequency events like homicide and the universal importance of research on homicide prevention, replicating and extending Nivette and colleagues' findings on homicide is imperative.

Third, compulsory mandates other than stay-at-home orders have remained in place long after the lockdowns were softened or removed. Have other pandemic-related restrictions like limits on group gatherings, work-from-home policies, and mask-wearing also influenced the opportunity for crime? Research should assess the longer-term reach of these measures on both macro-level (i.e., city) and 
micro-level (i.e., individual) patterns of offending.

This study by the Nivette team is ground-breaking because it provides global, concrete answers to COVID-19inspired crime questions that have proven surprisingly difficult to answer. However, the importance of the Nivette et al. study goes beyond COVID-19 because it teaches us something actionable about crime prevention and policy: across different countries, cultures, and societies, crime may be able to be reduced by simply altering structures that provide the opportunity to commit crime.

A universal truth is that crime, public health, and social policy are all intertwined. In a world where many policy-based attempts to reduce crime have failed, Nivette and her team may have just provided the spark that criminal justice personnel, policymakers, researchers, and public health officials need to reduce crime. If this is true, then COVID-19-despite all of its detrimental implications for life up to this point-may ironically be a catalyst that produces policies that improve the quality of life of hundreds of millions or billions of people worldwide.

John H. Boman IV D 1,2凶 and

Thomas J. Mowen ${ }^{1,2}$

${ }^{1}$ Department of Sociology, Bowling Green State University, Bowling Green, OH, USA. ${ }^{2}$ Center for Family and Demographic Research, Bowling Green State University, Bowling Green, $\mathrm{OH}$, USA.

凶e-mail:jboman@bgsu.edu

Published online: 11 June 2021

https://doi.org/10.1038/s41562-021-01151-3

References

1. Nivette, A. E. et al. Nat. Hum. Behav. https://doi.org/10.1038/ s41562-021-01139-z (2021).

2. Piquero, A. R., Jennings, W. G., Jemison, E., Kaukinen, C. \& Knaul, F. M. J. Crim. Just. 74, 101806 (2021).

3. Boman, J. H. IV \& Gallupe, O. Am. J. Crim. Justice 45, 537-545 (2020).
4. Felson, M., Jiang, S. \& Yanqing, X. Crime Sci. 9 , 10 (2020).

5. Ashby, M. P. J. Crime Sci. 9, 6 (2020).

6. United Nations, Department of Economic and Social Affairs, Population Division. World Population Prospects 2019 (2020); https://population.un.org/wpp

7. Proyecciones Poblacionales. Ecuador Instituto Nacional de Estadistica y Censos (2020); https://www.ecuadorencifras.gob.ec/ proyecciones-poblacionales/

8. 2019 Population in localities, by population group, end of 2019 . Israel Central Bureau of Statistics (2020); https://www.cbs.gov. il/he/publications/doclib/2017/population_madaf/population_ madaf_2019_1.xlsx

9. Selected Data on Municipalities, Slovenia, Annually. Republic of Slovenia Statistical Office (2020); https://pxweb.stat.si/SiStatData/ pxweb/en/Data/Data/2640010S.px/

10. 2020 world population data sheet. PRB.org (2021); https://www. prb.org/2020-world-population-data-sheet/

\section{Acknowledgements}

This work was supported in part by the Center for Family and Demographic Research, Bowling Green State University, which has core funding from the Eunice Kennedy Shriver National Institute of Child Health and Human Development (P2CHD050959).

Competing interests

The authors declare no competing interests. 